\title{
A New Control Strategy for Bi-directional DC/DC Converter in DC Microgrid
}

\author{
Tianze Miao, Xiaona Liu, Siyuan Liu and Lihua Wang* \\ College of Electronic and Information Engineering, Shandong University of Science and Technology, Qingdao, Shandong, China 266590
}

\begin{abstract}
The bi-directional DC / DC converter in DC microgrid is a typical nonlinear system which has large voltage disturbance during lead accumulator charging and discharging. In order to solve the problem of voltage disturbance, the linearization of the converter is realized by exact feedback linearization, and the sliding mode controller is designed by using exponential approximation law. The simulation results show that the method has fast response speed, strong anti-interference ability and good steady-state characteristics.
\end{abstract}

\section{INTRODUCTION}

The bi-directional DC / DC converter is a typical nonlinear system. Linear control method can be applied to bi-directional DC / DC converter. Precise feedback linearization is a common method in the application of DC / DC converter linearization, which has attracted the attention of some researchers due to its high precision [12]. The core of this method is to make the nonlinear system realize accurate linearization of state or inputoutput through appropriate nonlinear state and coordinate transformation, thus transforming the complex nonlinear system synthesis problem into the linear system synthesis problem [3]. In reference [4], the linear control method of precise feedback linearization is applied to the control of bi-directional DC / DC converter with satisfactory results.

The sliding mode control method has a strong robustness to the external disturbances. And it has been widely used in all kinds of power electronic converters because of its inherent switching characteristics [5]. In reference [6], taking the boost converter as an example, the global sliding mode control technology is adopted to ensure the stability of the system and to have faster response speed. In reference [7], it is proved that the principle of integer order sliding mode control is also effective for systems represented by fractional order operators. In reference [8], the finite time quantization feedback control is considered for the first time to solve the finite time tracking problem. In reference [9], a new concept of reaching rate is proposed, which can make the system state approach the sliding surface quickly when it is far away from or close to the sliding surface, and the reaching speed is zero when reaching the sliding surface, which can weaken the chattering better.

Based on the inspiration of the above papers, in order to improve the anti-interference ability of the DC bus voltage of the microgrid, a feedback linearization sliding mode variable structure control method is proposed.

\section{Linearization of Converters}

The bi-directional Buck-Boost converter using complementary conduction method, and the two states are shown in Figure 1.

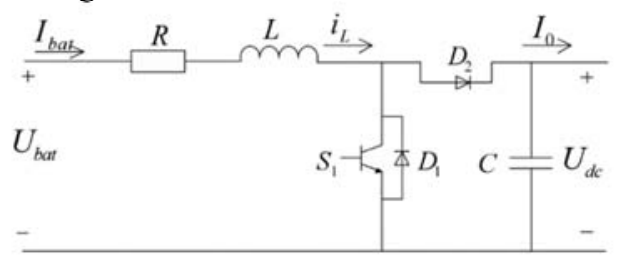

(a) The Boost converter is working

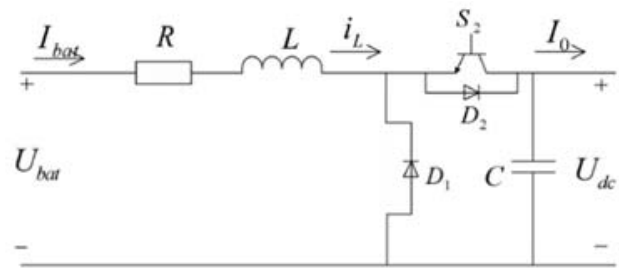

(b) The Buck converter is working

Figure 1. Two states of bi-directional DC/DC converter

If $x=\left[\begin{array}{ll}U_{d c} & i_{L}\end{array}\right]^{T}$ and $u=\left[\begin{array}{ll}I_{0} & U_{b}\end{array}\right]^{T}$, Statespace model is given by:

$$
\begin{gathered}
\dot{x}=\left[\begin{array}{l}
\left.\mathrm{d} A_{1}+(1-d) A_{2}\right] x+\left[d B_{1}+(1-d) B_{2}\right.
\end{array}\right] u \\
=\left[\begin{array}{cccc}
0 & \frac{1-d}{C} \\
-\frac{1-d}{L} & -\frac{R}{L}
\end{array}\right]\left[\begin{array}{ccc}
U_{d c} & -\frac{1}{C} & 0 \\
i_{L} & 0 & \frac{1}{L}
\end{array}\right]\left[\begin{array}{c}
I_{0} \\
U_{b}
\end{array}\right]
\end{gathered}
$$

The state space equation of the converter can be expressed as the following affine linear standard equation:

\footnotetext{
* Corresponding author: wanglihua7141@163.com
} 


$$
\left\{\begin{array}{c}
\dot{X}=f(x)+g(x) u \\
y=h(x)=x_{2}-U_{r e f}
\end{array}\right.
$$

In equation(2), $X=\left[x_{1} x_{2}\right]^{T}=\left[\begin{array}{ll}i_{L} & U_{d c}\end{array}\right]^{T}$ is the state variable, $f(x)=\left[\frac{U_{b}}{L}-\frac{x_{2}}{L} \quad \frac{x_{1}}{C}-\frac{x_{2}}{C R}-\frac{P}{C x_{2}}\right]^{T}, \quad g(x)=$ $\left[\frac{\mathrm{x}_{2}}{\mathrm{~L}}-\frac{\mathrm{x}_{1}}{\mathrm{C}}\right]^{\mathrm{T}}, \mathrm{u}=\mathrm{d}, \mathrm{y}$ is the output and $\mathrm{U}_{\text {ref }}$ is the reference value of bus voltage.

According to the requirements of feedback linearization, $\omega(\mathrm{X})$ must satisfy the following equation:

$$
L_{g}(X)=\frac{\partial \omega(X)}{\partial X} g(X)=0
$$

Chose new state variables as follows:

$$
\omega(X)=\frac{1}{2} L x_{1}^{2}+\frac{1}{2} C x_{2}^{2}
$$

According to the above formula, the defined output function is the total energy storage of bi-directional DC/DC converter, which provides a clear physical basis for the control method. According to the calculation, it can be calculated that:

$$
\begin{aligned}
L_{f} \omega(x) & =\frac{\partial \omega(x)}{\partial x} f(X)=U_{b a t}-\frac{x_{2}^{2}}{R}-P \\
L_{g} L_{f} \omega(x) & =\frac{\partial L_{f} \omega(x)}{\partial x} g(x)= \\
& =\frac{U_{b a t} x_{2}}{L}+\frac{2 x_{1} x_{2}}{C R} \\
L_{f}^{2} \omega(x)= & \frac{\partial L_{f} \omega(x)}{\partial x} f(X)= \\
= & \frac{U_{b a t}}{L}-\frac{U_{b a t} x_{2}}{L}+\frac{2 x_{2}^{2}}{C R^{2}}+\frac{2 P}{C R}
\end{aligned}
$$

Coordinate transformation can be carried out in the following ways:

$$
\left\{\begin{array}{c}
\dot{Z}_{1}=\frac{1}{2} L x_{1}^{2}+\frac{1}{2} C x_{2}^{2} \\
Z_{2}=U_{b a t} x_{1}-\frac{x_{2}^{2}}{R}-P
\end{array}\right.
$$

Then the relation between the new control variable $\mathrm{v}$ and the original control variable of the system is as follows:

$$
U=\frac{-L_{f}^{2} \omega(x)+v}{L_{g} L_{f} \omega(x)}
$$

\section{Design of Sliding Mode Variable Structure Controller}

The biggest difference between sliding mode control and other control methods is that the structure of the system is not fixed, but always in dynamic change. Sliding mode control can make the system move up and down with small amplitude and high frequency along the predetermined trajectory under certain characteristics. At the same time, the sliding mode can be designed, independent of system parameters and disturbances. Therefore, the system has good anti-interference ability in sliding mode motion.

$$
\left\{\begin{array}{c}
e_{1}=Z_{1}-Z_{r e f} \\
\dot{e}=\dot{Z}_{1}-\dot{Z}_{r e f}=Z_{2}-\dot{Z}_{r e f}
\end{array}\right.
$$

With $e_{1}$ being the tracking error and $Z_{r e f}$, the reference of $Z_{1}$, the first Lyapunov functions is defined as:

$$
\dot{V}_{1}=V_{1}+\frac{1}{2} e_{2}^{2}
$$

Substituting Equation (11) in to Equation (10), we get

$$
\begin{aligned}
\dot{e}_{2} & =v+c_{1} m_{1}-\ddot{Z}_{r e f} \\
& =L_{f}^{2} \omega(x)+L_{g} L_{f} \omega(x) U+c \dot{e}_{1}-Z_{r e f}
\end{aligned}
$$

Substituting Equation (12) in to Equation (11):

$$
\begin{aligned}
& \dot{V}_{2}=\dot{V}_{1}+e_{2} \dot{e}_{2}=e_{1} e_{2}-c_{1} e_{1}^{2}+ \\
& +e_{2}\left(L_{f}^{2} \omega(x)+L_{g} L_{f} \omega(x) U+c \dot{e}_{1}-\ddot{Z}_{r e f}\right)
\end{aligned}
$$

Therefore, the sliding mode plane can be represented as:

$$
S=e_{2}
$$

The exponential approach rate selected by sliding mode approach rate selects as:

$$
\dot{S}=-\varepsilon \operatorname{sgn}(s)-K s
$$

According to Equations (13) and (15), the selected control rate $\mathrm{U}$ is:

$$
U=\frac{-L_{f}^{2} \omega(x)-c_{1} \dot{e}_{1}+\ddot{Z}_{r e f}-e_{1}--\varepsilon \operatorname{sgn}(s)-K s}{L_{g} L_{f} \omega(x}
$$

After precise feedback linearization, the system has become a linear system. The sliding mode controller is connected to the system, and its control strategy can be represented by the program block diagram shown in Figure 2.

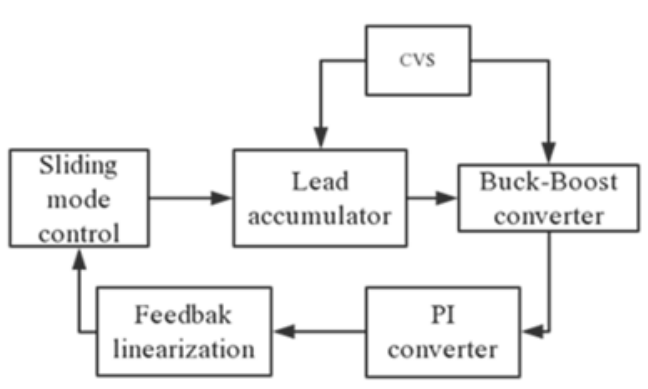

Figure 2. System program block diagram. 


\section{Simulation Analysis}

In order to verify the effectiveness of the control method in DC microgrid, the simulation model of sliding mode variable structure bidirectional buck boost converter based on precise feedback linearization is established. The controller is shown in Table 1.

Table 1. Model parameter setting.

\begin{tabular}{|c|c|}
\hline $\begin{array}{c}\text { Experimental } \\
\text { parameters }\end{array}$ & Value \\
\hline $\begin{array}{c}\text { Standard } \\
\text { voltage }\end{array}$ & $400 \mathrm{~V}$ \\
\hline Resistance( $\mathrm{R})$ & $30 \Omega$ \\
\hline Inductance(L) & $0.002 \mathrm{H}$ \\
\hline Capacitance $(\mathrm{C})$ & $0.001 \mathrm{~F}$ \\
\hline
\end{tabular}

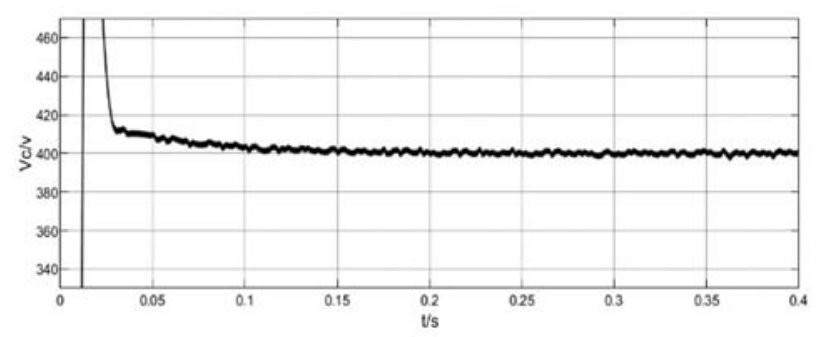

(a) Precise optimization control

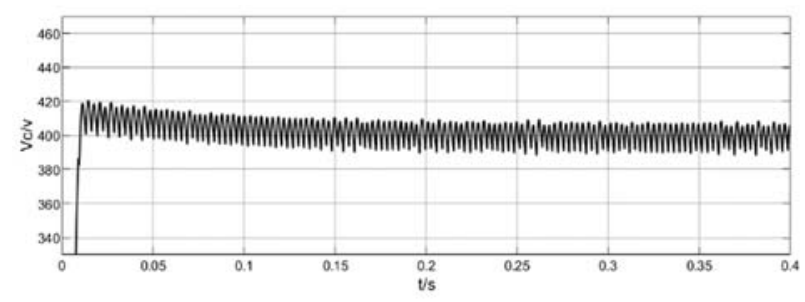

(b)Precise optimization control

Figure 3. Bus voltage transient response diagram

It can be seen from Figure 3 that in the start-up phase of battery network structure, the response time of optimized bus voltage is shorter than that of traditional PI control bus voltage response time, and it can enter steady state faster with smaller ripple.

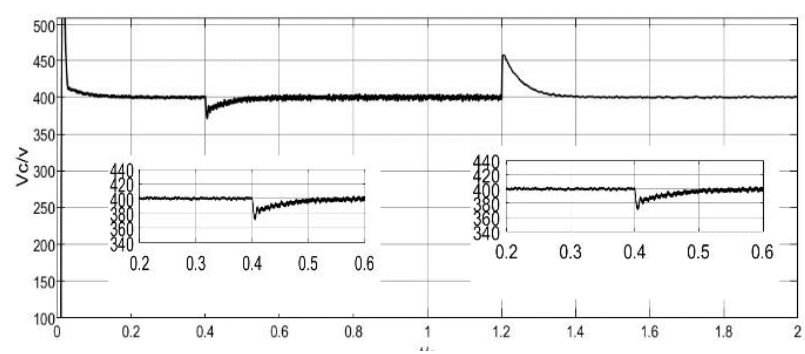

(a) Precise optimization control

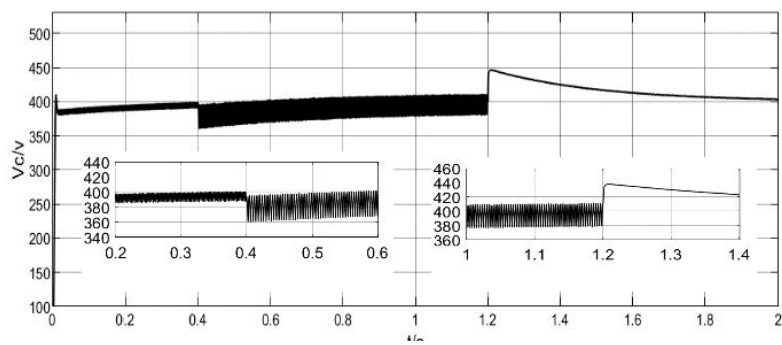

(b) Precise optimization control

Figure 4. Comparison of bus voltage waveforms

Figure 4 shows the variation of DC bus voltage waveform. It can be seen that when $t=0.4 \mathrm{~s}$, the load characteristic becomes the consumption of battery power. Figure 4 (a) can make a faster response according to external changes. The DC current is about $0.49 \mathrm{~s}$. When the bus is restored to $400 \mathrm{~V}$ standard voltage, it is still stable.

\section{Conclusion}

In the DC microgrid, the nonlinear variable structure control theory is introduced according to the nonlinear characteristics of bidirectional DC / DC converter. Based on the precise feedback linearization, a sliding mode variable structure controller is established. The simulation results show that the sliding mode control method based on precise feedback linearization can improve the dynamic response of the converter and enhance the antiinterference ability of the converter when the external conditions of the system change.

\section{References}

1. Amir. N, Mohammad. T, Two-axis Gimbal System Stabilization Using Adaptive Feedback Linearization[J]. Recent Advances in Electrical \& Electronic Engineering, 2020 13(3):355-368.

2. Ding. S, Xie. XP, Liu. YJ. Event-triggered static/dynamic feedback control for discrete-time linear systems [J]. Information Sciences, 2020(524): $33-45$.

3. Yang. JX, Wang. JH, Sun. ST. Nonlinear Contrrol of Boost Converter with Constant Power load [J]. Journal of Liaoning Technical University, 2020 (4):338 - 343.

4. Chen. HT, Hu. J, Han. XY, Qin. YJ. Research on nonlinear control strategy of DC/DC converters in DC microgrid [J]. Modern Electronics Technique, 2019 42(4):153-157.

5. P. P. Singh, B. K. Roy, Microscopic Chaos Control of Chemical Reactor System Using Nonlinear Active plus Proportional Integral Sliding Mode Control Technique, The European Physical Journal Special Topics, Vol.228, No.1, 2019, pp. 169-184.

6. I. Gian, R. Matteo, F. antonella, Sliding Mode Control of Constrained Nonlinear Systems, IEEE 
Transactions on Automatic Control, 2017(62)6:29652972.

7. L. Benadero,R. Cristiano, D. J. Pagano, Nonlinear analysis of interconnected power converters: A case study, IEEE Journal on Emerging and Selected Topics in Circuits and Systems, 2015(5)3:326-335.

8. Menhmet. E, Fractional order sliding mode control with reaching law approach[J]. Turkish Journal of Electrical Engineering and Computer Sciences, 2010 18(5):731-748.

9. You. WY, Zhang. YC, Wei. L, Liu. Shuai. Research of Sliding-Mode Control for Boost Converter Based on a Novel Reaching Rate[J]. Electrical \& Energy Management Technology, 2015(23):49-53. 